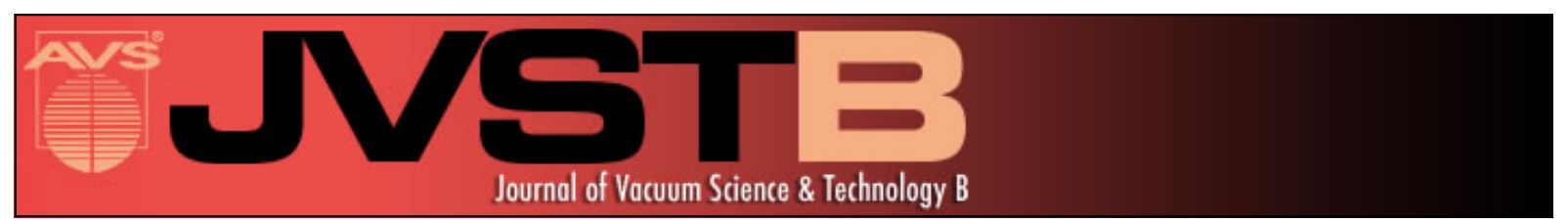

\title{
Metal-assisted etching of silicon molds for electroforming
}

Ralu Divan, Dan Rosenthal, Karim Ogando, Leonidas E. Ocola, Daniel Rosenmann, and Nicolaie Moldovan

Citation: Journal of Vacuum Science \& Technology B 31, 06FF03 (2013); doi: 10.1116/1.4821651

View online: http://dx.doi.org/10.1116/1.4821651

View Table of Contents: http://scitation.aip.org/content/avs/journal/jvstb/31/6?ver=pdfcov

Published by the AVS: Science \& Technology of Materials, Interfaces, and Processing

\section{Articles you may be interested in}

Electron transport characteristics of silicon nanowires by metal-assisted chemical etching

AIP Advances 4, 031307 (2014); 10.1063/1.4866578

Influence of catalytic gold and silver metal nanoparticles on structural, optical, and vibrational properties of silicon nanowires synthesized by metal-assisted chemical etching

J. Appl. Phys. 112, 073509 (2012); 10.1063/1.4757009

Nanofabrication of $x$-ray zone plates using ultrananocrystalline diamond molds and electroforming J. Vac. Sci. Technol. B 28, C6P30 (2010); 10.1116/1.3501357

Integration of benzocyclobutene polymers and silicon micromachined structures using anisotropic wet etching J. Vac. Sci. Technol. B 22, 2439 (2004); 10.1116/1.1787519

In-plane control of morphology and tunable photoluminescence in porous silicon produced by metal-assisted electroless chemical etching

J. Appl. Phys. 91, 6134 (2002); 10.1063/1.1465123

\section{HIDEN}

\section{Instruments for Advanced Science}

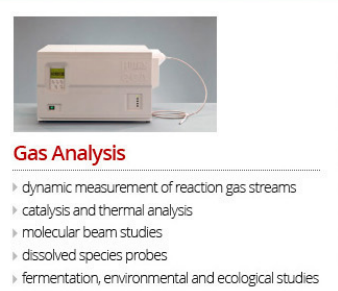

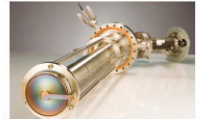

Plasma Diagnostics plasma source characterization etch and deposition process reaction

SIMS elemental imaging - surface mapping
, analysis of neytrat and radicat species

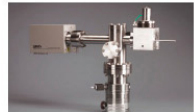

Vacuum Analysis , partial pressure measurement and contro of process gases reactive sputter process control vacuum diagnostics vacuum coating process monitoring 


\title{
Metal-assisted etching of silicon molds for electroforming
}

\author{
Ralu Divan ${ }^{\text {a) }}$ \\ Center for Nanoscale Materials, Argonne National Laboratory, 9700 S-Cass Avenue, Argonne, Illinois 60439 \\ Dan Rosenthal \\ Illinois Mathematics and Science Academy, 1500 Sullivan Road, Aurora, Illinois 60506 \\ Karim Ogando \\ Centro Atomico Bariloche and Instituto Balseiro, R.N., 8400, Argentina \\ Leonidas E. Ocola and Daniel Rosenmann \\ Center for Nanoscale Materials, Argonne National Laboratory, 9700 S-Cass Avenue, Argonne, Illinois 60439 \\ Nicolaie Moldovan \\ Advanced Diamond Technologies, Inc., 48 E. Belmont Drive, Romeoville, Illinois 60446
}

(Received 21 June 2013; accepted 3 September 2013; published 18 September 2013)

\begin{abstract}
Ordered arrays of high-aspect-ratio micro/nanostructures in semiconductors stirred a huge scientific interest due to their unique one-dimensional physical morphology and the associated electrical, mechanical, chemical, optoelectronic, and thermal properties. Metal-assisted chemical etching enables fabrication of such high aspect ratio Si nanostructures with controlled diameter, shape, length, and packing density, but suffers from structure deformation and shape inconsistency due to uncontrolled migration of noble metal structures during etching. Hereby the authors prove that a Ti adhesion layer helps in stabilizing gold structures, preventing their migration on the wafer surface while not impeding the etching. Based on this finding, the authors demonstrate that the method can be used to fabricate linear Fresnel zone plates. (C) 2013 American Vacuum Society.
\end{abstract}

[http://dx.doi.org/10.1116/1.4821651]

\section{INTRODUCTION}

The efficient formation of organized silicon nanostructures with high aspect ratios is highly desired due to the potential applications in fields ranging from solar energy conversion ${ }^{1}$ to chemical/biological sensors ${ }^{2,3}$ and microfluidics. ${ }^{4,5}$ Numerous fabrication methods for such structures have been developed, using approaches such as vapor-liquid-solid deposition/ growth, ${ }^{6}$ laser ablation, ${ }^{7}$ and thermal evaporation decomposition, ${ }^{8}$ but require either high temperatures or long synthesis times. Other methods, such as wet etching techniques, are limited in aspect ratio or geometrical characteristics of the structures, while dry chemical methods are well known for their high aspect ratio performance, ${ }^{9}$ but require expensive tools. Historically, metal assisted etching of silicon has been first reported by Dimova-Malinovska et al. ${ }^{10}$ and was recently refined into a simple, fast, and effective high aspect ratio nanostructures formation method by Peng et al. ${ }^{11}$ The method, known under the abbreviations MachEtch ${ }^{12}$ or MaCE, ${ }^{13}$ allows the fabrication of a wide range of silicon nanostructures on large surfaces, ranging from nanowires to high aspect ratio pores, to bundles of wires of different dimensions. ${ }^{14,15}$ The method is simple, low-cost, and offers controllability of structural parameters such as diameter, length, orientation, morphology, porosity, etc., of the nanostructures. ${ }^{16}$ The technique uses a combination of a $\mathrm{Si}$ surface oxidant (e.g., $\mathrm{H}_{2} \mathrm{O}_{2}$ ) and hydrofluoric acid (HF) in conjunction with a noble metal (e.g., $\mathrm{Au}, \mathrm{Ag}$, or $\mathrm{Pt}$ ) as catalyst, ${ }^{17}$ in the shape of a patterned thin film atop the silicon surface. The oxidant injects holes through the metal-semiconductor interface to oxidize the

${ }^{a)}$ Electronic mail: divan@anl.gov semiconductor layer underneath and the hydrofluoric acid dissolves the oxidized semiconductor into soluble products. As a result, the metal descends into the semiconductor, producing a three-dimensional semiconductor structure. The overall reaction of MacEtch of $\mathrm{Si}$ in a solution of $\mathrm{H}_{2} \mathrm{O}_{2}$ and $\mathrm{HF}$ catalyzed by Au can be written as ${ }^{15}$

$$
\mathrm{Si}+\mathrm{H}_{2} \mathrm{O}_{2}+6 \mathrm{HF} \rightarrow 2 \mathrm{H}_{2} \mathrm{O}+\mathrm{H}_{2} \mathrm{SiF}_{6}+\mathrm{H}_{2} \uparrow .
$$

The partial reactions at the cathode $(\mathrm{Au})$, and anode ( $\mathrm{Si}$ substrate), can be written, respectively, as

$$
\begin{aligned}
& \mathrm{Si}+4 \mathrm{~h}^{+} \rightarrow \mathrm{Si}^{4+} \text { (cathode) }, \\
& 2 \mathrm{H}^{+}+2 \mathrm{e}^{-} \rightarrow \mathrm{H}_{2}(\text { anode }) .
\end{aligned}
$$

A related mechanism is known under the name "galvanic attack" for polysilicon etching/staining in presence of $\mathrm{Au}$ patterns in the case of etching $\mathrm{SiO}_{2}$ sacrificial layers in buffered HF etch, in MEMS processes ${ }^{18}$ such as multi-user MEMS processes (MUMPs) or Sandia ultra-planar multilevel MEMS technology (SUMMIT). ${ }^{19,20}$ While the galvanic attack is a parasitic effect, MacEtch puts this process to good use for nanostructure fabrication. Although the MacEtch process is intrinsically anisotropic, methods have been developed to control the etching direction, enabling the fabrication of vertically aligned $\mathrm{Si}$ nanowires (SiNWs) on (100) and non-(100) substrates, or in certain inclined directions on non-(100) substrates. ${ }^{21}$

The combination of metal patterning and MacEtch of silicon was successfully used to achieve precise positioning of aligned SiNWs. By combining catalytic etching and 
nanosphere lithography, large scale fabrication of SiNW arrays with controlled location was demonstrated. ${ }^{22,23}$ The MacEtch in conjunction with block-copolymer lithography was successfully used to create ordered and densely packed arrays of high aspect ratio single crystal silicon nanowires. ${ }^{24}$ Large areas of high-density SiNW arrays were produced by MacEtch of silicon by using porous anodic aluminum oxide as a patterning mask for the noble metal. ${ }^{25}$ The use of this technique made possible to control the average diameter of the SiNWs down to $8 \mathrm{~nm}$. The combination of optical lithography and MacEtch was also used as an effective means to prepare vertically aligned SiNW arrays grouped in micronsized features. ${ }^{26,27}$

A commonly reported drawback of the MacEtch technique is the lateral migration of the metal structures during etching, resulting in deformed or totally contorted $\mathrm{Si}$ structures. $^{28}$

In this paper, we report on using a $\mathrm{Ti}$ adhesion layer between silicon and gold, which resulted in a substantially reduced migration. The benefit of using a Ti layer for reducing migration is discussed in several approaches for the fabrication of silicon nanostructures by the combination of optical lithography, interference lithography, and electron beam lithography and MacEtch. Reduced migration is critical to high accuracy MacEtch fabrication, such as for high aspect ratio linear Fresnel zone plates (FZPs), which are exemplified. In this case, the Si structures configured by MacEtch were used as a mold for electroplating, having the initial Au layer as a plating base.

\section{EXPERIMENT}

The selective formation of silicon nanostructures followed the sequence shown in Fig. 1. Boron doped, p-type $\mathrm{Cz}-\mathrm{Si}$ (100) substrates with 5-10 $\Omega \mathrm{cm}$ resistivity were used in this study. The silicon substrates were first cleaned with Nanostrip solution at $120^{\circ} \mathrm{C}$ for $20 \mathrm{~min}$, rinsed with deionized (DI) water, dehydrated at $150^{\circ} \mathrm{C}$, and treated with hexamethyldisilazane in a priming oven (YES 310). For optical lithography and interference lithography ma-N 1405

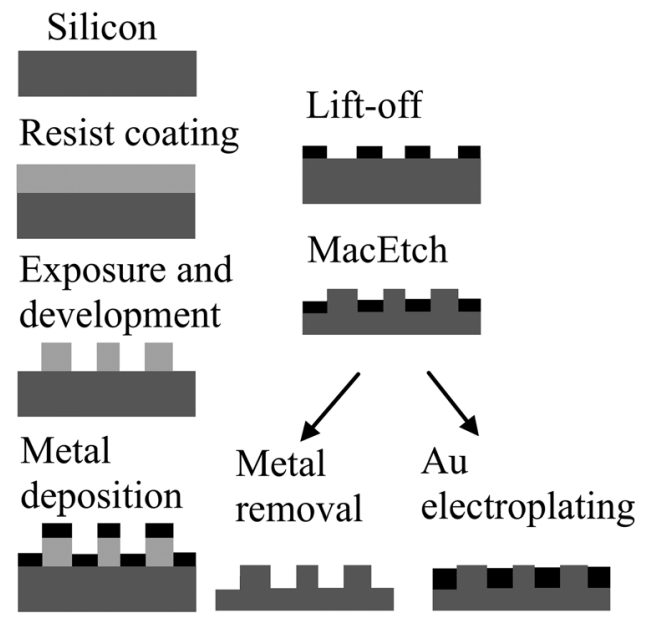

FIG. 1. Sequence used for the fabrication of Si structures by MacEtch.
(MicroChem) negative resist diluted 1:2 with anisole was used. The resist was spin-coated at $4000 \mathrm{rpm}$ for $35 \mathrm{~s}$ and baked on a hot plate at $100^{\circ} \mathrm{C}$ for $90 \mathrm{~s}$, which resulted in a resist thickness of $88 \mathrm{~nm}$ as measured with a F-40 spectroscopic reflectometry system (Filmetrics, Inc.). The optical lithography was carried out with a MA6 mask aligner (Karl Suss), using a power density of $25 \mathrm{~mW} / \mathrm{cm}^{2}$ and exposure time $15 \mathrm{~s}$. Interference lithography was carried out with a three-beam Lloyd's mirror setup as described by de Boor. ${ }^{29}$ The resulting pattern, a nanohole array with hexagonal symmetry, was obtained by a single exposure and developing process. The setup consisted of a $\mathrm{HeCd}$ laser $(\lambda=325 \mathrm{~nm}$, $30 \mathrm{~mW}$ ), an electronic shutter to control the exposure time, a beam expander lens with a spatial filter consisting of a 10$\mu$ m-diameter pinhole, and a stage with rotating adjustment, two mirrors, and a sample holder. The two mirrors were mounted perpendicular to the sample surface, forming an angle of $120^{\circ}$ with respect to each other. With the mirrors and sample rigidly fixed relative to each other, the angle of interference, and thus, the period of the interference pattern were set by rotating the mirror/substrate assembly around the point of intersection of the mirrors and the substrate. The interference pattern period is given by $P=\lambda /(1.5 \times \sin (\theta))$, where $\lambda$ is the wavelength of the laser light, and $\theta$ is the angle between the incident laser beam and the normal to the sample surface. An angle of incidence of $15^{\circ}$ resulted in an interference period of $\sim 835 \mathrm{~nm}$. The interference exposure of the resist was $360 \mathrm{~s}$. For e-beam lithography ma N-2405 (MicroChem) negative resist diluted 1:2 with anisole was used, with the same deposition and treatment conditions as above. The resist thickness was $88 \mathrm{~nm}$. Electron beam patterning was done on a Raith $150 \mathrm{e}-$ beam lithography system, with an acceleration voltage of 20 $\mathrm{keV}$, beam current of $38 \mathrm{pA}$, and a dose of $80-120 \mu \mathrm{C} / \mathrm{cm}^{2}$. The patterns were developed in ma-D $533 \mathrm{~S}$ (MicroChem) developer for $10 \mathrm{~s}$, rinsed with DI water, and dry-blown with nitrogen gas. The resist residues were removed in $\mathrm{O}_{2}$ plasma (C1702 March), at a pressure of $160 \mathrm{mT}$, power $20 \mathrm{~W}$ for $20 \mathrm{sec}$. The samples were immersed in buffer oxide etch for $30 \mathrm{~s}$, rinsed with DI water, and dry-blown with nitrogen before depositing the metal. The metal deposition (Au or Ti/Au) was performed in a Lesker PVD-250 electron-beam evaporator with a Sigma deposition controller at a base pressure of $10^{-8}$ Torr. After the metal lift-off in 1165 remover, the samples were rinsed with DI water and dried with nitrogen.

To produce MacEtch Si structures, we used a solution of $\mathrm{HF}, \mathrm{H}_{2} \mathrm{O}_{2}$, and $\mathrm{H}_{2} \mathrm{O}$ in a volumetric ratio of $4: 1: 15$. The etching was performed at two different temperatures, $20^{\circ} \mathrm{C}$ and $10^{\circ} \mathrm{C}$, in room light illumination. After etching, the samples were rinsed with DI water and gently dried with nitrogen or with the critical point dryer (Bal-Tec CPD 030) for the high density, high aspect ratio patterns. On some samples, the Au was removed with Au etchant (Transene Inc.); on others, $\mathrm{Au}$ was used as a plating base for electroplating. A Techni-gold $25 \mathrm{E}$ solution (Technic Inc.) with gold sulfite $\left[\mathrm{Au}\left(\mathrm{SO}_{3}\right)_{2}\right] \mathrm{Na}_{3}$ as active ingredient was used for electroplating. The plating was performed at $40^{\circ} \mathrm{C}$, and current density of $1 \mathrm{~mA} / \mathrm{cm}^{2}$. 


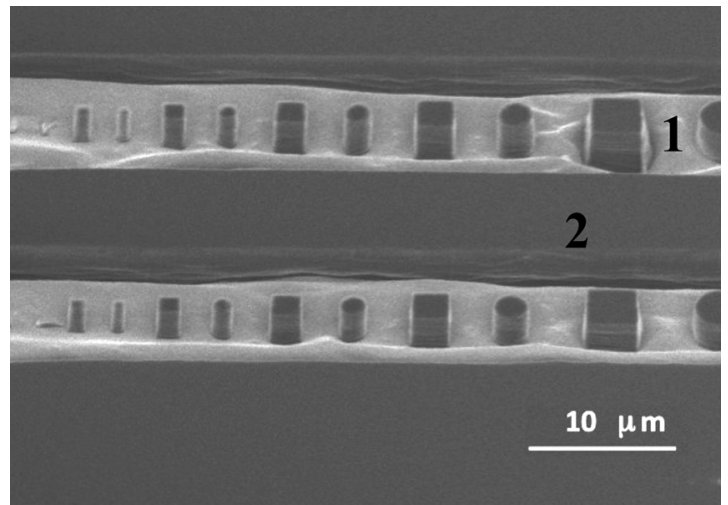

FIG. 2. SEM images of Si columns of square and round cross section and varying diameters/sides from $100 \mathrm{~nm}$ to $2 \mu \mathrm{m}$ obtained by gold-assisted chemical etching (with no adhesion layer). Gold was patterned with e-beam lithography and lift-off. 1 -gold; $2-$ Si.

The scanning electron microscope (SEM) images were obtained using a FEI Nova 600 SEM.

\section{RESULTS AND DISCUSSION}

The detailed geometries of the resulting $\mathrm{Si}$ structures depend on the initial shape of the noble metal pattern. Figure 2 shows an SEM image of Au strips with columnar Si structures produced by the sinking of a patterned gold layer into the Si substrate during the MacEtch process. The shapes of the holes in the gold layer correspond to the different cross sections of the Si columns. The 20-nm-thick gold layer was patterned in this case by e-beam lithography and lift-off. Despite being anchored in the remaining Si columns, the gold strips start to delaminate, showing wobbled edges. However, the Si columns seem not to suffer from the gold delamination.

A similar situation is encountered when etching arrays of pillars with a simple gold mask patterned by interference lithography and lift-off, as depicted in Fig. 3(a). The anchoring into pillars seems to be effective in preventing the gold

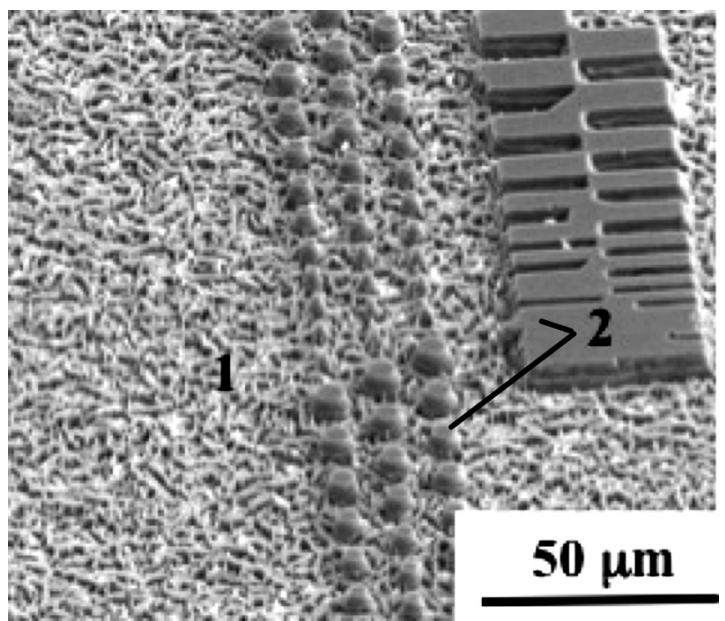

FIG. 3. SEM images of an array of Si pillars after gold-assisted etching (a) and after gold electroplating (b). The gold mask was fabricated by interference lithography and lift-off. migration during etching. In the case of isolated small groups of columns resulted from MacEtch of large goldcovered areas with corresponding small groups of holes, the $\mathrm{Si}$ columns are undeformed, but the etched $\mathrm{Si}$ surface is rough (Fig. 4). The roughing of the Si surface under the metal mask is likely a consequence of the delamination and loose contact between the gold and $\mathrm{Si}$, since the $\mathrm{Si}$ surface under well-adhering gold layers was observed to be much smoother. Other authors reported that the etched Si surface roughness is determined by either the ratio $[\mathrm{HF}] /[\mathrm{HF}]$ $\left.+\left[\mathrm{H}_{2} \mathrm{O}_{2}\right]\right)^{30}$ or by the bubbles of $\mathrm{H}_{2}$ created during the etching process that stick to the substrate and shield the silicon surface from the etchant, leading to the roughing of the etched surface. ${ }^{31}$ Both observations are consistent with the loose gold layer roughing explanation, since the concentration of reactants and byproducts in the confined space between the loose gold and $\mathrm{Si}$ are expected to vary locally, while bubbles can get trapped between the gold and Si. However, an electrochemical-driven roughing of the Si surface due to random contact between the wrinkled gold mask and $\mathrm{Si}$ is also plausible.

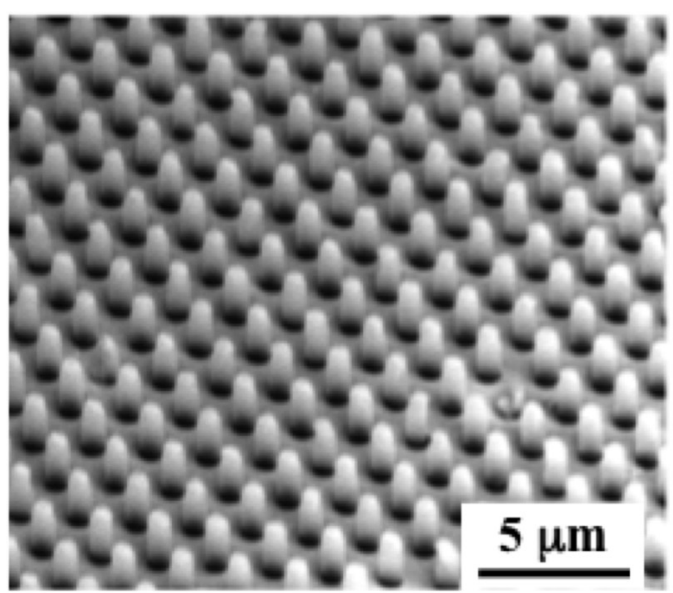

(a)

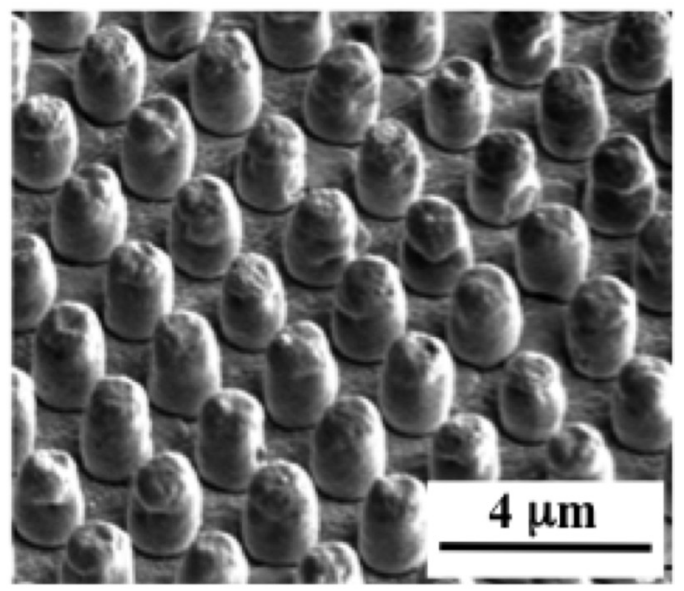

(b)

FIG. 4. SEM image of a Si surface after MacEtch for $30 \mathrm{~min}$ using a pure gold mask. 1-roughened Si surface, as developed under a loose gold catalyst layer; 2-Si structures. The gold mask was removed in this picture. 


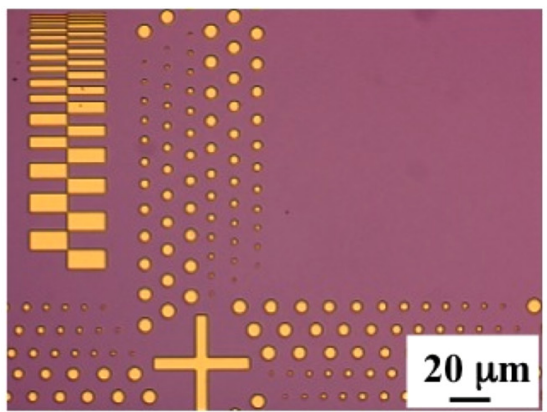

(a)

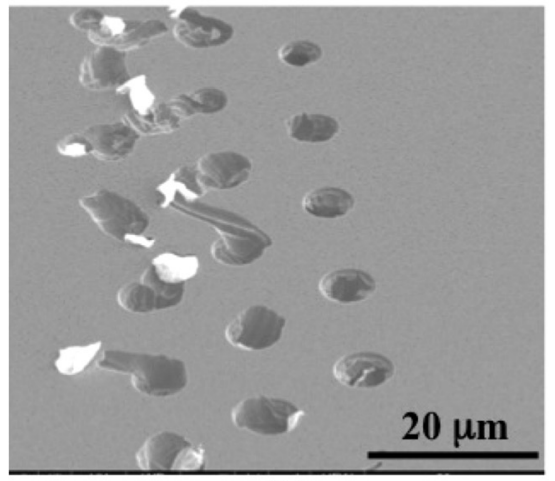

(b)

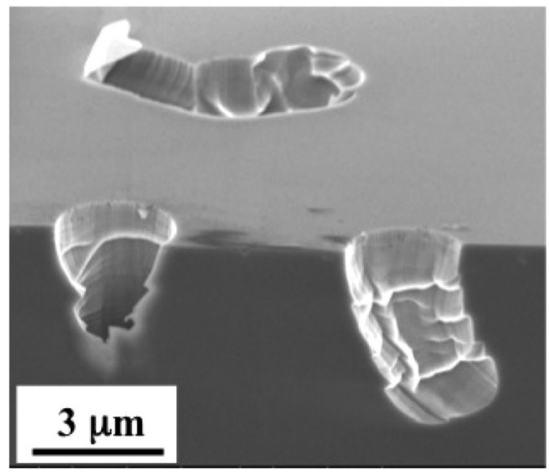

(c)

FIG. 5. (Color online) (a) Optical image of Au dot array after patterning and lift-off. Dots were patterned by optical lithography and have sizes varying from 1 to $7 \mu \mathrm{m}$; gold catalyst layer has opposite polarity to the one used in Fig. 4. (b) SEM image showing the lateral migration movement of Au particles on the Si surface. (c) Cross section in a pattern similar to (b), showing contorted pore wells resulting from the volume migration of dots during MacEtch.

The gold structures' migration during MachEtch is more pronounced with small isolated gold dots, as can be seen in Fig. 5. The gold pattern shown in Fig. 5(a) is similar to the one in Fig. 4, but with opposite polarity. The test mask has an array of gold dots varying in diameter from 1 to $7 \mu \mathrm{m}$. The migration of the gold dots on the Si surface is visible in Fig. 5(b). Figure 5(c) shows that the gold dots also move and deform while inside the pores etched into $\mathrm{Si}$, creating contorted pores. Huang et al. ${ }^{28}$ reported a similar tendency for isolated $\mathrm{Ag}$ particles on (110) substrate, although the inside$\mathrm{Si}$ migration is somewhat crystal-orientation dependent: in the initial stage of etching, the $\mathrm{Ag}$ particles moved along the $\langle 100\rangle$ direction and, with increasing etching time, some groups of particles changed their initial direction and moved collectively in other crystallographic directions. Our results with simple gold dots do not show a crystal-orientation dependence of the bulk migration.

From our analysis, we concluded that the gold pattern surface migration takes place predominantly at the beginning of the process. Therefore, a $4 \mathrm{~nm}$ Ti layer between $\mathrm{Au}$ and $\mathrm{Si}$ was proposed in order to enhance the adhesion of gold to the $\mathrm{Si}$ surface and, therefore, stabilize the structures. The experimental results showed not only an unmodified etching behavior, but also a surprisingly reduced migration both on the $\mathrm{Si}$ surface and in the $\mathrm{Si}$ volume. Figure 6(a) shows an aerial view of a large area test pattern with Ti/Au dots used for etching deep pores into Si. No surface-migrated dots and deformed patterns can be observed, but instead a uniformly etched, accurately placed arrays of holes over the whole imaged area was obtained. This is a substantial improvement with respect to the case of MacEtch with simple Au dots presented in Fig. 5(b). Figure 6(b) presents a cross section through one of the arrays of varying diameter dots and pores, which shows that the lateral migration of the $\mathrm{Ti} / \mathrm{Au}$ dots inside the Si volume is also reduced during MacEtch. This figure also shows a size effect in the depth of etching pores

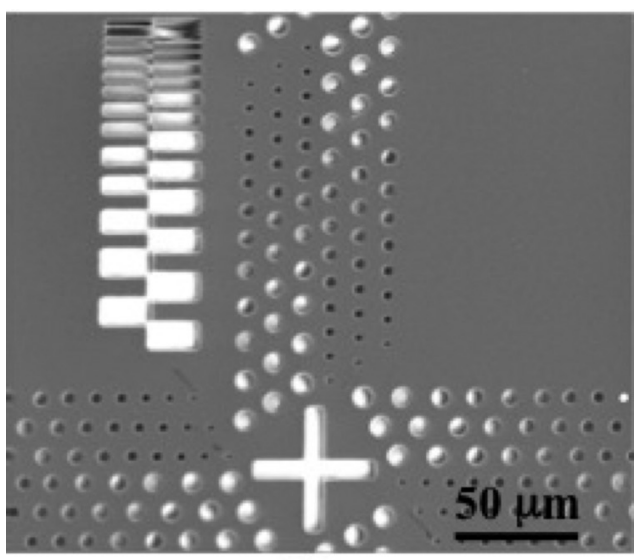

(a)

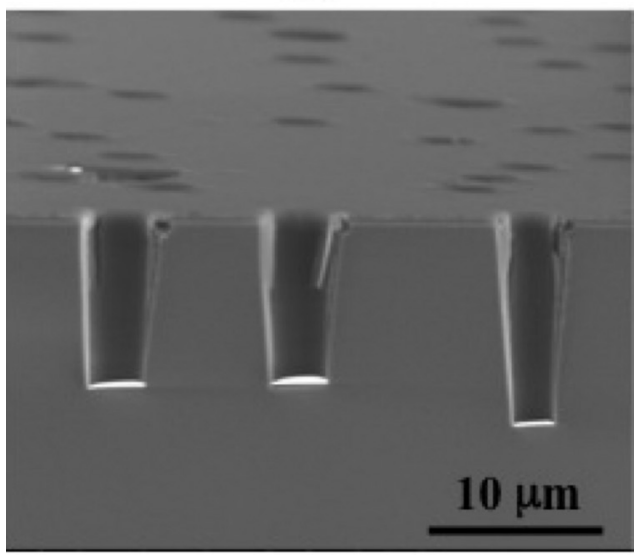

(b)

FIG. 6. SEM images of a hole array similar to the case presented in Fig. 5, fabricated by MacEtch using 4-nm-tick Ti film as adhesion layer for the gold mask. (a) Top image, showing pores with resident gold dots inside; (b) Cross section view, showing the improvement in vertical lining as compared to Fig. 5(c). 
with metal dots, whereas smaller dots sink deeper/faster into the Si than larger dots. A size effect for etching Si columns starting from holes in the metal (Fig. 2) was not observed. A future study will be dedicated to this effect.

\section{A. MacEtch molds for electroforming}

MacEtch Si structures are well suited for electroforming molds because the metal at the bottom of the etched structures can be used directly as a plating base. The MacEtch fabricated Si arrays of pillars shown in Fig. 3(a) were used as molds for gold electroplating. In Fig. 3(b), it can be seen that the gold is growing not only from bottom to top but also uniformly around the Si pillars, thus creating a 3-D electroforming structure. The deposition on the Si pillars can be caused by the field concentration in the electrolyte around the high aspect ratio Si pillars; however, the gold deposition in this case seems conformal around the pillars, a sign that a gold contamination of the side-walls of the pillars may make them more conductive. However, gold contamination of the sidewalls was ruled out by the energy dispersive $\mathrm{x}$-ray examination of sample Si columns detached from the substrate. A subsequent explanation could be the injection of holes from the gold into $\mathrm{Si}$, similar to the MacEtch process, only here happening for the electrodeposition process of gold from solution. Injected holes from the bottom gold layer into the $\mathrm{Si}$

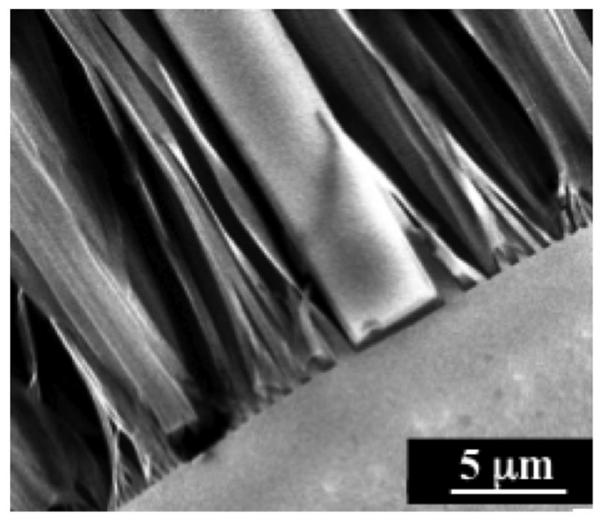

(a)

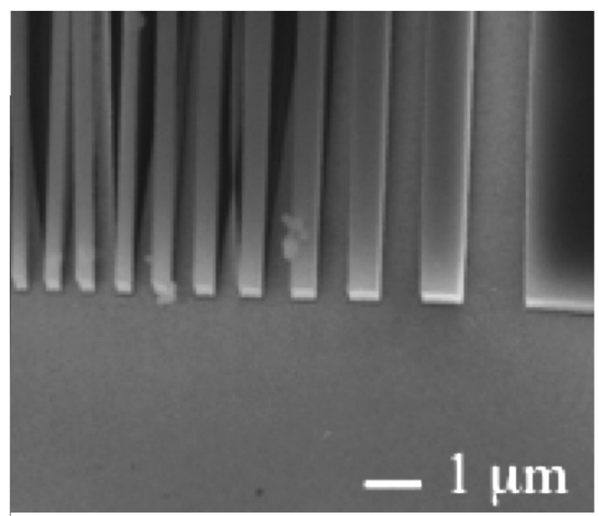

(b)

FIG. 7. SEM images of linear zone plate etched by Au-assisted etching: (a) without adhesion layer and etched at $20^{\circ} \mathrm{C}$, (b) with $4 \mathrm{~nm}$ Ti film as adhesion layer, dried with CPD.

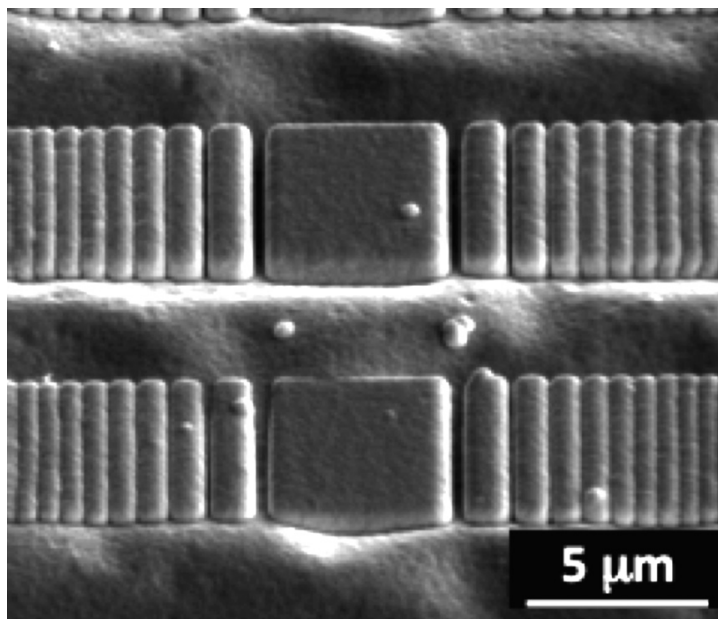

FIG. 8. Linear zone plate electroplated with Au after Au-assisted etching.

columns may make them more conductive and thus transform them into more effective electrodes for gold plating.

As an immediate application, gold electroplating in MacEtch Si molds was used for the fabrication of linear FZPs for x-rays focusing. Among many x-ray microfocusing optics developed so far, FZPs are the most promising both for hard $x$-ray ${ }^{32}$ and soft $\mathrm{x}$-ray spectral regions. ${ }^{33}$ The diffraction limit of FZPs corresponds to 1.2 times the width of the outermost zone. Spot sizes in the range of tens of nanometers for soft $\mathrm{x}$-rays ${ }^{34}$ and of about $50 \mathrm{~nm}$ for hard $\mathrm{x}$-rays ${ }^{35}$ have been achieved. There are two main difficulties in the fabrication process of a FZP for the hard $\mathrm{x}$-ray spectral region: First, the pattern generated should provide high resolution and high placement accuracy for a large number of curved lines with continuously varying line width. Second, the structures have to be transferred into the phase-shifting material with high aspect ratios and controlled high thickness. For the energy region from 8 to $20 \mathrm{keV}$, this translates into a range of gold phase-shifter thicknesses from 1.6 to $3.5 \mu \mathrm{m}$. Here we performed the fabrication of $\mathrm{x}$-ray linear FZPs by e-beam lithography, MacEtch to form Si molds, and subsequent electroforming of gold.

Although our first linear FZPs prototypes showed a strong Au delamination as in Fig. 7(a), the addition of a Ti adhesion layer, along with drying the sample with critical point drying, produced a remarkable improved structure shown in Fig. 7(b). For complete linear FZPs fabrication we used a wet process that excludes the drying steps between the MacEtch and the final Au electroplating. ${ }^{36}$ Figure 8 shows the SEM image of a linear FZPs fabricated by MacEtch and electroplating.

\section{CONCLUSIONS}

3D silicon structures with length scales ranging from micrometers to sub- $100 \mathrm{~nm}$ were fabricated by combining different metal patterning lithographies and metal assisted etching. MacEtch enabled the fabrication of Si nanostructures with controlled size, shape, length, and packing density without the need of sophisticated RIE techniques. The use of $\mathrm{Ti}$ as an adhesion layer eliminated the lateral migration and 
reduced lateral volume migration of the gold pattern during the Si metal assisted etching, resulting in high aspect ratio structures with smooth vertical walls, high geometrical accuracy, and high wafer-level uniformity. Subsequent to MacEtch of $\mathrm{Si}$, the metal layer was successfully used as a plating base for electroforming using the Si nanopatterns as a mold. We have demonstrated that due to the added Ti adhesion layer, the technique can be successfully applied to soft X-ray linear FZPs fabrication. However, other challenges have to be addressed before the method can be applied for functional hard $\mathrm{x}$-ray FZPs fabrication.

\section{ACKNOWLEDGMENTS}

Use of the Center for Nanoscale Materials, Argonne National Laboratory was supported by the U. S. Department of Energy, Office of Science, Office of Basic Energy Sciences, under Contract No. DE-AC02-06CH11357. The submitted manuscript has been created by UChicago Argonne, LLC, Operator of Argonne National Laboratory ("Argonne"). Argonne, a U.S. Department of Energy Office of Science laboratory, is operated under Contract No. DE-AC02-06CH11357.

${ }^{1}$ W. Kern et al., Nano Lett. 10, 1582 (2010).

${ }^{2}$ F. Patolsky, G. Zheng, and C. M. Lieber, Anal. Chem. 78, 4260 (2006).

${ }^{3}$ Y. Hea, C. Fanc, and S.-T. Lee, Nano Today 5, 282 (2010).

${ }^{4}$ N. Verplanck, E. Galopin, J.-C. Camart, V. Thomy, Y. Coffinier, and R. Boukherroub, Nano Lett. 7, 813 (2007).

${ }^{5}$ M. Jönsson-Niedziolka, F. Lapierre, Y. Coffinier, S. J. Parry, F. Zoueshtiagh,

T. Foat, V. Thomy, and R. Boukherroub, Lab Chip 11, 490 (2011).

${ }^{6}$ B. Salhi, B. Gelloz, N. Koshida, G. Patriarche, and R. Boukherroub, Phys. Status Solidi A 204, 1302 (2007).

${ }^{7}$ A. M. Morales and C. M. Lieber, Science 279, 208 (1998).

${ }^{8}$ D. P. Yu, Appl. Phys. Lett. 72, 3458 (1998).

${ }^{9}$ Y. Q. Fu, A. Colli, A. Fasoli, J. K. Luo, A. J. Flewitt, A. C. Ferarri, and W. I. Milne, J. Vac. Sci. Technol. B 27, 1520 (2009).

${ }^{10}$ D. Dimova-Malinovska, M. Sendova-Vassileva, N. Tzenov, and M. Kamenova, Thin Solid Films 297, 9 (1997).

${ }^{11}$ K. Q. Peng, J. J. Hu, Y. J. Yan, Y. Wu, H. Fang, Y. Xu, S. T. Lee, and J. Zhu, Adv. Funct. Mater. 16, 387 (2006).
${ }^{12}$ X. Li, Curr. Opin. Solid State Mater. Sci. 16, 71 (2012).

${ }^{13}$ M. Zahedinejad, S. D. Farimani, M. Khaje, H. Mehrara, A. Erfanian, and F. Zeinali, J. Micromech. Microeng. 23, 055015 (2013).

${ }^{14}$ L. Boarino, M. Destro, S. Borini, N. Pugno, A. Chiodoni, F. Bellotti, and G. Amato, Phys. Status Solidi A 206, 1250 (2009).

${ }^{15}$ Z. Huang, N. Geyer, P. Werner, J. de Boor, and U. Gösele, Adv. Mater. 23, 285 (2011).

${ }^{16}$ X. Li and P. W. Bohn, Appl. Phys. Lett. 77, 2572 (2000).

${ }^{17}$ K. Balasundaram et al., Nanotechnology 23, 305304 (2012).

${ }^{18} \mathrm{E}$. Chan, "Characterization and modeling of electrostatically actuated polysilicon micromechanical devices," Ph.D. dissertation (Department of Electrical Engineering, Stanford University, 1999).

${ }^{19}$ MEMSCAP Inc., "PolyMUMPS design guidelines and rules," see: http:// www.memscap.com/products/mumps/polymumps/reference-material.

${ }^{20}$ Sandia National Laboratory, Multi-level MEMS Technology 5 (SUMMiT VTM), see: http://mems.sandia.gov/tech-info/summit-v.html.

${ }^{21}$ Z. Huang, T. Shimizu, S. Senz, Z. Zhang, N. Geyer, and U. Gösele, J. Phys. Chem. C 114, 10683 (2010).

${ }^{22}$ Z. Huang, H. Fang, and J. Zhu, Adv. Mater. 19, 744 (2007).

${ }^{23}$ K. Peng, M. Zhang, A. Lu, N.-B. Wong, R. Zhang, and S.-T. Lee, Appl. Phys. Lett. 90163123 (2007).

${ }^{24}$ S.-W. Chang, V. P. Chuang, S. T. Boles, C. A. Ross, and C. V. Thompson, Adv. Funct. Mater. 19, 2495 (2009).

${ }^{25}$ Z. Huang, X. Zhang, M. Reiche, L. Liu, W. Lee, T. Shimizu, S. Senz, and U. Gösele, Nano Lett. 8, 3046 (2008).

${ }^{26}$ L. J. Wan, W. L. Gong, K. W. Jiang, H. L. Li, B. R. Tao, and J. Zhang, Appl. Surf. Sci. 255, 3752 (2009).

${ }^{27}$ N. Megouda, G. Piret, E. Galopin, Y. Coffinier, T. Hadjersi, O. Elkechai, and R. Boukherroub, Appl. Surf. Sci. 258, 6007 (2012).

${ }^{28}$ Z. P. Huang, T. Shimizu, S. Senz, Z. Zhang, X. X. Zhang, W. Lee, N. Geyer, and U. Gösele, Nano Lett. 9, 2519 (2009).

${ }^{29}$ J. de Boor, N. Geyer, U. Gösele, and V. Schmidt, Opt. Lett. 34, 1783 (2009).

${ }^{30}$ C. Chartier, S. Bastide, and C. Levy-Clement, Electrochim. Acta 53, 5509 (2008).

${ }^{31}$ B. S. Aldinger, A. Gupta, I. T. Clark, and M. A. Hines, J. Appl. Phys. 107, 103520 (2010).

${ }^{32}$ B. Lai et al., Appl. Phys. Lett. 61, 1877 (1992).

${ }^{33}$ S. J. Spector, C. J. Jaconsen, and D. M. Tenant, J. Vac. Sci. Technol. B 15, 2872 (1997).

${ }^{34}$ E. H. Anderson, D. L. Olynick, B. Harteneck, E. Veklerov, G. Denbeaux, W. Chao, A. Lucero, L. Johnson, and D. Attwood, J. Vac. Sci. Technol. B 18, 2970 (2000).

${ }^{35}$ W. Yun et al., Rev. Sci. Instrum. 70, 2238 (1999).

${ }^{36}$ R. Divan, D. C. Mancini, N. Moldovan, B. Lai, L. Assoufid, Q. Leonard, and F. Cerrina, Proc. SPIE 4783, 82 (2002). 